\title{
Hommage à Gérard LE GRAND
}

Dans le premier numéro de l'année 2015, de Gestion et Finances publiques - La Revue, Gérard Le Grand passait les commandes de la rédaction en chef à Michel Le Clainche, au terme de 10 années au cours desquelles il en avait assumé la responsabilité.

Nous lui souhaitions alors, comme il était légitime et comme nous en avions sincèrement le désir pour lui, une "bonne et heureuse retraite».

Elle n'aura été que de courte durée : notre ami s'en est allé à la mi-janvier, trop vite, trop tôt, trop mal.

Mais il nous laisse le souvenir d'une carrière exemplaire et, surtout, celui d'un homme exceptionnel.

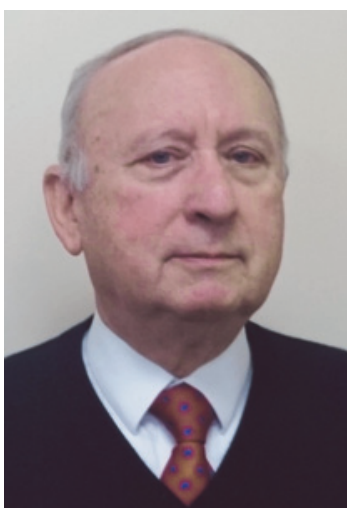

Rédacteur en chef (2005 - 2015)

Économiste de formation, il se rattachait au courant philosophique du personnalisme. Ancien élève d'HEC et de l'ENA, il intègre la Caisse des Dépôts (CDC) en juin 1968.

Il y prendra des responsabilités grandissantes, tant en province qu'au siège et terminera ce brillant cursus par 5 années à la tête de la CNP.

C'est alors, en 1992, qu'il rejoint le Ministère des Finances pour une nouvelle étape de sa carrière, comme Trésorier payeur Général.

Saône-et-Loire, Finistère, Puy-de-Dôme et Auvergne ont eu la chance d'accueillir ce grand serviteur de l'État, aux vastes compétences mises au service du plus grand nombre.

L'estime de ses collègues Trésoriers payeurs Généraux et Receveurs des Finances le porte alors, à la Présidence de leur association, une mission qu'il assumera jusqu'à sa retraite.

Une retraite active puisqu'il conserve des activités en lien avec sa première carrière à la CDC et, puisqu'il prend la charge de rédacteur en chef de la revue, à l'époque «Revue du Trésor».

II sera l'instigateur, l'ouvrier de son évolution en fonction des transformations administratives en cours, notamment la fusion DGI-DGCP, il aura à cœur de préserver l'héritage reçu des collègues qui nous ont précédés, tout en s'attachant à renforcer et à développer la qualité de la revue, l'intérêt de ses études, l'ouverture à des auteurs d'horizon et de points de vue différents.

Son souci de diffuser le savoir aura été intact jusqu'au bout : nous lui sommes reconnaissants de ses objectifs, de son action pour les atteindre et de ses conseils toujours bienveillants.

Mais si nous connaissons bien le collègue, nous connaissons aussi, car c'était la même personne, l'ami.

Fidèle, généreux et toujours présent : c'est lui qui va nous manquer, lui à qui nous allons penser souvent.

Et nous connaissons aussi celui qu'il a été pour sa famille, celui qu'il voulait être, le souci qu'il avait de chacun de ses membres.

À son épouse, à ses enfants et petits enfants, l'équipe de Gestion et Finances publiques - La Revue adresse ses bien sincères et très affectueuses condoléances. 